East African Medical Journal Vol. 80 No. 8 August 2003

DIAGNOSTIC POTENTIAL OF SERUM VITAMIN E TOCOPHEROL AND CHOLESTEROL LEVELS IN CHILDREN WITH PROTEIN ENERGY MALNUTRITION IN WESTERN KENYA

A.M. Kwena, BSc, MSc, Lecturer and H.S. Nyandieka, PhD, Professor, Department of Medical Biochemistry, Faculty of Health Sciences, Moi University, P.O. Box 4606, Eldoret, Kenya

Request for reprints to: Mr. A.M. Kwena, Department of Medical Biochemistry, Faculty of Health Sciences, Moi University, P.O. Box 4606, Eldoret, Kenya

\title{
DIAGNOSTIC POTENTIAL OF SERUM VITAMIN E TOCOPHEROL AND CHOLESTEROL LEVELS IN CHILDREN WITH PROTEIN ENERGY MALNUTRITION IN WESTERN KENYA
}

\author{
A.M. KWENA and H.S. NYANDIEKA
}

\begin{abstract}
Objective: To determine the levels and diagnostic potential of vitamin $\mathrm{E}$ ( $\alpha$-tocopherol) in protein energy malnutrition (PEM) in western Kenya.

Design: Passive Hospital based study conducted on inpatients and outpatients.

Setting: Webuye sub-District and Moi Teaching and referral Hospitals, Western Kenya.

Subjects and Methods: Serum levels for vitamin $\mathbf{E}$ and cholesterol concentrations in children $<5$ years of age $(n=56)$ admitted to Webuye District Hospital, Bungoma, Western Kenya and some (n=3) admitted to Moi teaching and referral Hospital, Eldoret Kenya suffering from Kwashiorkor, Marasmus or PEM and malaria plus there controls, for a period of one year (January- December, 2001) were examined. High Performance Liquid Chromatography (HPLC) and Spectrophotometry were used for the analysis.

Results: The serum vitamin E levels were higher in Kwashiorkor $(0.078 \mathrm{mg} / \mathrm{ml}$, SD 0.034$)$ than marasmus $(0.075 \mathrm{mg} / \mathrm{ml}$; SD 0.069$)$ and controls $(0.057 \mathrm{mg} / \mathrm{ml}$; SD 0.022). The mean serum cholesterol levels were higher in marasmus $(204.6 \mathrm{mg} / \mathrm{dl}$; SD 104.8) than Kwashiorkor (186.0 mg/dl; SD 119.3) and controls (154.3; SD 33.3). There was a significant correlation in vitamin $E$ concentrations between Kwashiorkor and controls only at $P<0.01$ as compared to Marasmus and Marasmic/Kwashiorkor. Vitamin E levels did not show significant correlation to cholesterol in malnourished children from Webuye, Bungoma in western Kenya at $\mathbf{P}<\mathbf{0 . 0 1}$.
\end{abstract}

Conclusion: Vitamin E could be a useful diagnostic tool for PEM in this area.

\section{INTRODUCTION}

Vitamin E, the fat soluble antioxidant was first discovered in 1922 (1).Vitamin E actions are mainly antioxidant and effects of its deficiency in humans are still controversial (2). It is present in human tissues and widely distributed in foods, so primary deficiency of the vitamin is unlikely. In paediatrics, it is accepted that deficiency in premature and small for date (age) infants results in haemolytic anaemia. Prophylactic vitamin E to prevent or treat deficiency is given routinely in some neonatal units. Its value as a counter to free radical excess situations is under investigation. Deficiencies of vitamin E and other antioxidants have also been shown to protect against malaria infection $(3,4)$. The explanation most frequently given is that the absence of antioxidants makes the parasite more vulnerable to damage by oxygen radicals produced by the immune system.

Severe protein energy malnutrition (PEM) describes a spectrum of clinical syndromes ranging from kwashiorkor to severe marasmus (5). Kwashiorkor is characterised by the presence of bipedal oedema and has a particularly high mortality rate. The pathogenesis of oedema in kwashiorkor is currently unresolved and most likely multi-factorial.
One theory (6) postulates that the imbalance between the production of free radicals and their neutralisation by scavengers plays an important role in the development of the kwashiorkor syndrome. These radicals which are end products of the inflammatory pathway generate peroxides particularly in cell membranes. Unscavenged radicals damage tissues and induce leakage. The concentrations of a number of molecules that protect radicals in PEM particularly in kwashiorkor include vitamin $\mathrm{E}(\alpha-$ tocopherol) $(2,3,7)$ amongst others. The explanation for this reduced concentrations may be due to overconsumption or reduced synthesis. The objective of this study was to determine the serum concentrations of vitamin $\mathrm{E}$ ( $\alpha$-Tocopherol) in children $<5$ years suffering from kwashiorkor or marasmus alone or in combination with malaria and to determine its possible protective effect in children suffering from both PEM and malaria under hospital conditions (8).

\section{MATERIALS AND METHODS}

Study area: Webuye sub-District Hospital is situated in Bungoma District Western Kenya. This is located about 70 Kilometres from Eldoret town. The region is situated at an elevation of about 2,100 metres above sea level quite proximal 
to Mt. Elgon District. The District also borders Uganda on its western side. It experiences two rainy seasons: March/ July for long rains and August/October for the short rains. Malnutrition and Malaria are endemic in the region probably due to over dependence on sugar cane as a cash crop in the region (9).

Study population: Children aged five years or less admitted to Webuye sub-District Hospital. Those diagnosed to have complications from other infections apart from malaria were excluded.

Consent: This was received from the parents or guardians of the children prior to the study. Official consent was also received from the relevant government ministries and departments to carry out the research in the study area.

Design: This was a passive Hospital based study conducted on inpatients and outpatients (MCH clinic) at the hospital. No randomisation was carried out. Three groups of children were sampled. Those with severe Kwashiorkor or marasmus, those with both kwashiorkor and malaria and control children free from the two disease conditions. A total of about 60 children were sampled.

Blood: Five to eight millilitres of blood samples were taken in sterile vaccutainer tubes from each subject. The blood was centrifuged and serum separated and stored at $-20^{\circ} \mathrm{C}$ (Webuye sub-District Hospital) and later transported in a cool box with ice cubes to Moi teaching and referral hospital for storage at $-70^{\circ} \mathrm{C}$ until required for assay of the vitamin $\mathrm{E}$ status in the three groups of children

Extraction of $\alpha$ Tocopherol from serum: One hundred $\mu 1$ of internal standard, tocopherol acetate stock solution was added to $100 \mu \mathrm{l}$ of serum sample and the resulting mixture vortexed. One thousand $\mu \mathrm{l}$ of hexane was then added and vortexed for $10 \mathrm{~s}$. This was followed by centrifugation at $2000 \mathrm{rpm}$ for 10 min. Eight hundred $\mu$ l of supernatant (hexaan phase) was transferred to a clear tube and dried at $40^{\circ} \mathrm{C}$ under a stream of nitrogen gas. One hundred $\mu \mathrm{l}$ methanol was added to dried sample and $20 \mu 1$ sample injected in the HPLC column for the assay.

High performance liquid chromatography HPLC analysis: Concentrations of Vitamin E ( $\alpha$-tocopherol) were measured by HPLC with fluorescence detection (10-12) using tocopherol acetate as the internal standard. Commercial $\alpha$-tocopherol was used as the external standard. Twenty $\mu 1$ samples were injected onto a CRI C18 $300 \mathrm{~mm}$ x 4.0, 100 microns (HICHROM) column. A flow rate of $2.0 \mathrm{ml} / \mathrm{min}$ with a mobile phase of methanol and an SPD- 10AV vP (shimadzu) detector with excitation and emission wavelength of 292 and $298 \mathrm{~nm}$ were used. The $\alpha$-tocopherol component of the internal standard, tocopherol acetate was detected first having a retention time of approximately 4 min followed by detection of $\alpha$ tocopherol at around $5 \mathrm{~min}$.

Analysis: Statistical analysis of the results were carried out using class-VP (Shimadzu, Japan) and SPSS 10 computer programme to determine any differences between the three groups of children studied. The mean, Standard Deviation, Chi square tests were carried out to compare the differences in concentrations of vitamin E in three groups of PEM . Spearman's correlation were used to compare the relation between age, height and weight in the three groups. A P-value of $<0.05$ was taken as significant.

Cholesterol assay of serum: Cholesterol was determined after enzymatic hydrolysis and oxidation of the EDTA-serum samples. The indicator, quinoneimine was formed from hydrogen peroxide and 4-aminophenazone in the presence of phenol and peroxidase. The spectrophotometric assay wavelength was 500 $\mathrm{nm}$ at an optical path of $1 \mathrm{~cm}$ and a temperature of $20-25{ }^{\circ} \mathrm{C}$. Measurement was carried out against a reagent blank. Only one reagent blank per series was used (Human Gesellschaft for Biochemica and Diagnostica, mbH, Germany). Ten $\mu \mathrm{l}$ of sample or standard was mixed with $1000 \mu \mathrm{l}$ of reagent. The resulting mixture was incubated at $10 \mathrm{~min}$ at $20-25^{\circ} \mathrm{C}$. The absorbance of the samples or standard was measured against the reagent blank within 60 minutes.

\section{RESULTS}

Study population: Characteristics of the study population are summarised in Table 1 .The table shows the mean Height (cms), Weight (Kgs) and age (months) of the study population and their respective standard deviations. The prevalence of marasmus in these hospital admissions was slightly higher than kwashiorkor. The mean age height and weight was higher in kwashiorkor than marasmus

HPLC: Representative chromatograms of $\alpha$ tocopherol for each of the children sampled showing peak levels at $292 \mathrm{~nm}$ frequencies were determined, to give the concentration of $\alpha$-tocopherol Differences in the concentrations of $\alpha$-tocopherol in the three groups of children calculated from a standard curve of ratios and concentrations of $\alpha$-tocopherol showed no statistically significant difference $(\mathrm{p}<0.05)$ in the three groups studied: kwashiorkor, marasmic/kwashiorkor and marasmus in comparison to their control samples.

Vitamin $E$ ( $\alpha$-tocopherol) assay: Table 2 shows the mean concentrations of vitamin E ( $\alpha$-tocopherol levels found in the three representative groups of children a. kwashiorkor b. marasmus c. PEM and malaria in comparison to control children who were free from any disease condition. The mean concentration of vitamin $\mathrm{E}$ was higher in children suffering from kwashiorkor than marasmus and controls. The differences were however not significant at $(\mathrm{p}<0.005)$. Control children showed the least mean concentration of vitamin $\mathrm{E}$. The values obtained in this study were much higher than reported values $(13,14)$, but they still showed the differences in the three groups of the study groups.

\section{Table 1 a}

Relative prevalence (\%) of kwashiorkor, marasmic / kwashiorkor and marasmus in some hospital admissions at Webuye, Bungoma, Western Kenya.

\begin{tabular}{lcc}
\hline PEM TYPE & No. & Prevalence $(\%)$ \\
\hline Kwashiorkor & $17 / 59$ & 28.8 \\
Marasmus & $19 / 59$ & 32.2 \\
Marasmic/Kwashiorkor & $11 / 59$ & 18.6 \\
PEM + Malaria & $40 / 59$ & 67.8 \\
Controls (Normal) & $12 / 59$ & 20.3 \\
\hline
\end{tabular}


Table 1 b

Characteristics of the hospital based study population (n=60): Webuye sub-District Hospital, Bungoma, Western Kenya

\begin{tabular}{lccc}
\hline & Mean Age (months) & Mean Height (cms) & $\begin{array}{c}\text { Mean Weight } \\
\text { (Kgs) }\end{array}$ \\
\hline Kwashiorkor & $31.2(\mathrm{n}=17) ;$ SD20.0 & $74.3(\mathrm{n}=15) ;$ SD9.9 & $9.0(\mathrm{n}=18) ;$ SD2.8 \\
Marasmus & $18.2(\mathrm{n}=19) ;$ SD15.1 & $70.9(\mathrm{n}=15) ;$ SD12.2 & $7.2(\mathrm{n}=19) ;$ SD1.8 \\
Oedema + malaria & $33.9(\mathrm{n}=24) ;$ SD19.8 & $76.6(\mathrm{n}=18) ;$ SD11.3 & $9.4(\mathrm{n}=22) ;$ SD2.9 \\
Malaria & $24.6(\mathrm{n}=40) ;$ Sd18.5 & $72.3(\mathrm{n}=25) ;$ SD8.8 & $8.5(\mathrm{n}=35) ;$ SD3.4 \\
Controls & $26.8(\mathrm{n}=6) ;$ SD 23.19 & ND & $11.65(\mathrm{n}=6) ;$ SD 5.62 \\
\hline
\end{tabular}

Figure 1

Mean concentrations of serum vitamin E from children with;

a) Kwashiorkor $(0.078 \mathrm{mg} / \mathrm{ml})$

b) Marasmic/Kwashiorkor $(0.075 \mathrm{mg} / \mathrm{ml})$

c) Marasmus $(0.075 \mathrm{mg} / \mathrm{ml})$

d) Controls $(0.057 \mathrm{mg} / \mathrm{ml})$

The values for malnourished children on recovery range between, $0.0-0.8 \mathrm{mg} / 100 \mathrm{ml}(0.00-0.008 \mathrm{mg} / \mathrm{ml})$.

Table $2 a$

Mean concentration of Vitamin $E$ ( $\alpha$-tocopherol) in serum of three groups of children suffering from PEM

\begin{tabular}{|c|c|c|c|c|}
\hline & $\begin{array}{c}\text { Kwashiorkor } \\
n=17\end{array}$ & $\begin{array}{c}\text { Marasmus } \\
\text { Kwashiorkor } \\
\mathrm{n}=19\end{array}$ & $\begin{array}{c}\text { Marasmic/Kwashiokor } \\
n=11\end{array}$ & $\begin{array}{l}\text { Control } \\
n=12\end{array}$ \\
\hline $\begin{array}{l}\text { Mean } \\
\text { Vitamin E } \\
\text { ( } \alpha \text {-tocopherol conc.) } \\
\mathrm{mg} / \mathrm{ml}\end{array}$ & $\begin{array}{c}0.078[\text { SD } 0.034] \\
\mathrm{n}=19\end{array}$ & $\begin{array}{c}0.075 \text { [SD 0.069] } \\
\mathrm{n}=17\end{array}$ & $\begin{array}{l}0.075[\text { SD } 0.03] \\
n=10\end{array}$ & $\begin{array}{c}0.057 \text { [SD 0.022] } \\
\mathrm{n}=11\end{array}$ \\
\hline \multicolumn{5}{|c|}{ Normal values $(4.0-19.4 \mu \mathrm{g} / \mathrm{ml})$} \\
\hline \multicolumn{5}{|c|}{ Table $2 b$} \\
\hline & $\begin{array}{c}\text { Kwashiorkor } \\
n=17\end{array}$ & $\begin{array}{c}\text { Marasmus } \\
\mathrm{n}=19\end{array}$ & $\begin{array}{l}\text { Marasmic/Kwashiorkor } \\
\mathrm{n}=11\end{array}$ & $\begin{array}{c}\text { Control } \\
\mathrm{n}=12\end{array}$ \\
\hline $\begin{array}{l}\text { Mean } \\
\text { cholesterol } \\
\text { levels } \\
(\mathrm{mg} / \mathrm{dl})\end{array}$ & 186[SD:119.3] & 204.6[SD:104.8] & 182[SD:103.8] & 154.25[SD:33.3] \\
\hline
\end{tabular}


Figure 2

\section{Concentrations of cholesterol in three groups of children suffering from PEM}

a) Kwashiorkor $(186 \mathrm{mg} / \mathrm{dl})$

b) Marasmic/Kwashiorkor $(182.1 \mathrm{mg} / \mathrm{dl})$

c) Marasmus $(294.6 \mathrm{mg} / \mathrm{dl})$

d) Controls $(154.3 \mathrm{mg} / \mathrm{dl})$

The values for malnourished children on recovery range between, $80-240 \mathrm{mg} / 100 \mathrm{ml}$

Cholesterol: The mean Cholesterol concentrations were higher in children suffering from marasmus as compared to kwashiorkor, marasmic/kwashiorkor and controls (Table 2a and Figure 2).

a. Interaction between history of malaria infection and vitamin $\mathrm{E}$ b. Cholesterol in malnourished children. There was no significant interaction between vitamin $\mathrm{E}$ and cholesterol with malaria at $\mathrm{p}<0.05$.

Table 3 a

Interaction between malaria and vitamin $E$ concentration in malnourished children

\begin{tabular}{lccc}
\hline $\begin{array}{l}\text { History of malaria and } \\
\text { vitamin E }\end{array}$ & No. & $\begin{array}{c}\text { Pearsons } \\
\text { Chi-square }\end{array}$ & P-value \\
\hline Kwashiorkor & 19 & 37.359 & $0.276^{*}$ \\
Marasmic/Kwashiorkor & 10 & 6.875 & $0.333^{*}$ \\
Marasmus & 17 & 13.240 & $0.352^{*}$ \\
Controls & 11 & 3.157 & $0.532^{*}$ \\
\hline
\end{tabular}

*Not significant at $\mathrm{P}<0.05$

Table $3 b$

Interaction between malaria and cholesterol concentration in malnourished children

\begin{tabular}{lccc}
\hline $\begin{array}{l}\text { History of malaria and } \\
\text { vitamin E }\end{array}$ & No. & $\begin{array}{c}\text { Pearsons } \\
\text { Chi-square }\end{array}$ & P-value \\
\hline Kwashiorkor & 17 & 51.0 & $0.357^{*}$ \\
Marasmic/Kwashiorkor & 11 & 11.0 & $0.358^{*}$ \\
Marasmus & 18 & 30.857 & $0.524^{*}$ \\
Controls & 12 & 12.0 & $0.285^{*}$ \\
\hline
\end{tabular}

- Not significant at $\mathrm{P}<0.05$
The levels in kwashiorkor and marasmic/ kwashiorkor were almost the same. Correlation of vitamin E concentrations in the three PEM states showed a significant correlation between kwashiorkor and controls at $\mathrm{P}<0.01$. There was no significant correlation between vitamin $\mathrm{E}$ and cholesterol concentration in the samples studied.

\section{DISCUSSION}

The prevalence of hospital admissions in Webuye, Bungoma during the period April-July for PEM showed higher cases of marasmus than Kwashiorkor. This is expected for this region (9).

The average age of kwashiorkor cases in hospital admission in Webuye was higher than similar studies carried out in Jamaica, Jordan, Baghdad, India and Lesotho (5). Marasmus was lower than that for India, but higher than for the countries above. The cases reported by Waterlow are for children aged $<3$ year only, whereas this study reports cases children aged $<5$ years. It should be noted that hospital admissions are subject to selection bias.

We have shown in this study that vitamin E levels in kwashiorkor correlate to control samples. This may imply that the concentration of vitamin $\mathrm{E}$ in kwashiorkor was similar to that in control samples, but marasmus and marasmic/kwashiorkor had different levels. So vitamin E could be of diagnostic significance in the latter two PEM states. There was no significant correlation between vitamin $\mathrm{E}$ and the cholesterol concentrations in the control samples. This implies there is no relationship between the two as earlier suggested by other workers

Plasma concentrations of vitamin $\mathrm{E}$ are diminished in marasmus and particularly in Kwashiorkor $(6,15)$. Vitamin $\mathrm{E}$ is transported by cholesterol-rich lipoproteins and plasma cholesterol is also reduced in PEM (16). The ratio of vitamin $\mathrm{E}$ to cholesterol was significantly reduced in a previous study in Kilifi, Kenya (15) leading to diminished resistance to oxidative stress.

Vitamin E ( $\alpha$-tocopherol) is a fat-soluble antioxidant that plays a vital role in scavenging of freeradicals that cause inflammation, leading to vascular leakage that results in oedema in kwashiorkor. Previous studies have indicated that deficiencies of vitamin $\mathrm{E}$ and other anti-oxidants tend to protect against malaria infection $(3,4)$. The explanation was that the absence of antioxidants makes the malaria parasite more vulnerable to damage by oxygen radicals produced by the immune system. The results obtained in this study do not agree with this concept since kwashiorkor children with lower vitamin $\mathrm{E}$ levels also had a history of malaria on admission. These results agree with findings of a similar study conducted in Kilifi, along the coast of Kenya (15). Other reports suggest that persons with lower plasma vitamin E levels recover more quickly from clinical malaria $(17,18)$. Since no follow up of the children studied was done, this hypothesis could not be confirmed from this study. The concentrations of vitamin $\mathrm{E}$ were higher in 
malnourished cases than their controls. This may imply that the vitamin has a role to play in biochemical activities that lead to malnutrition. Previous studies have indicated the role of vitamin $\mathrm{E}$ as a free radical scavenger that would lead to reduced inflammation in kwashiorkor (15). The concentration of vitamin E was slightly higher in Kwashiorkor than marasmus cases. The levels of a $\alpha$ tocopherol were lower in control children than kwashiorkor children contrary to the hypothesis vitamin E levels are less in kwashiorkor children' resulting in bipedal oedema.

The results reflect the true differences between the three groups of malnourished children and their controls. In addition, cholesterol levels were consistent with the vitamin E levels as recommended by Horwitt et al, (13). Given the different experimental conditions under which the analyses were carried out, first at Moi teaching and referral hospital, Eldoret, Kenya followed by confirmatory analyses at-Glaxosmithkline Pharmaceutical Company, Nairobi Kenya, the results reported may not give the precise concentrations of vitamin $\mathrm{E}$ in samples analysed, but only give the possible differences between the groups studied. Precise determination of the tocopherol concentrations was beyond the scope of this study.

We conclude that mean Vitamin E concentrations in kwashiorkor children were similar to controls. The concentration in kwashiorkor cases were slightly higher than marasmus cases, therefore the concentration was low in marasmus and marasmic/kwashiorkor cases. This is the reverse of the hypothesis postulated. The concentration of vitamin $\mathrm{E}$ does not seem to be affected by the malaria status of the children as shown by chi-square test at $\mathrm{P}<0.05$.

Mean Cholesterol concentrations were lower in children suffering from kwashiorkor than those with marasmus. There was no significant difference between the mean concentrations of both vitamin $\mathrm{E}$ and cholesterol. Possible causes of low concentrations of vitamin $\mathrm{E}$ especially in marasmus and marasmic/kwashiorkor could be reduced consumption through inadequate diet. Possible remedy for the situation would be through vitamin $\mathrm{E}$ supplementation and general community education on observing appropriate dietary regimes. Future recommendation would include incorporation of vitamin E administration alongside vaccinations in children $<5$ years of age for diseases such as measles. This exercise was recently successfully carried out by the Kenya Government (unpublished observations) during the period June 17-23, 2002 for vitamin A.

\section{ACKNOWLEDGEMENTS}

Parents and Guardians of children who participated in the study. Arthur Kwena acknowledges the financial support from The Netherlands co-operation for advancement of
Higher Education (Nuffic). Thanks go to staff of Webuye sub-District Hospital, Bungoma for assistance in collection of samples.

\section{REFERENCES}

1. Metzler D.E. In: Biochemistry: the chemical reactions of living cells. Academic Press. New York. P 428; 1977.

2. Elmadfa I., Wotruba F. and Wagner K .H. Gamma tocopheral: In vitro and in vivo antioxidant potential Ann. Nut. Metab. (suppl.1) 2001;45:592.

3. Shankar A.H., Nutritional modulation of malaria morbidity and mortality. J. Infec. Dis. 2000; 182(Supp II):S37-S53.

4. Levander O.A., and Ager A.1., Jr. Malarial Parasites and antioxidant nutrients. Parasitology; 1993; 107:S95-S106.

5. Waterlow. In: Protein Energy Malnutrition.2nd edn. Edward Amold. Publishers, London, 1992.

6. Golden M., and Ramdath D. Free radicals in the pathogenesis of kwashiorkor. Proc. Nutr. Soc. 1987; 46:53-60.

7. Nyandieka H.S. and Wakhisi J. The impact of vitamins A, C, $\mathrm{E}$ and selenium compound on prevention of liver cancer in rats. East. Afr. Med. J. 1993; 70:151-153.

8. Das B.S., Thurnham D.I., and Das D.B. Plasma $\alpha$-tocopherol; retinol and carotenoids in children with falciparum malaria. Am. J. Clin. Nutr. 1996; 64:94-100.

9. GOK-Development plan for Bungoma District, 2002-2008.

10. De Leenheer A.P., Lambert W.E. and Van Bocxlaer J.F. In: Modern Chromatographic Analysis of Vitamins. Third Edition, Revised and Expanded. Marcel Dekker Inc. Pub. New York, 2000.

11. De Leenheer A.P., De Bevere VORC, De Ruyter M.G.M. and Claeys A.E. Simultaneous determination of retinol and $\alpha$-tocopherol in human serum by high-performance liquid chromatography. J. Chrom., 1979; 162:408-413.

12. Ruyter de M.G.M., and Leeneheer de A.P., Determination ofserum retinol (vitamin A) by high speed liquid chromatography. Clin. Chem. 1976; 22:1593-1595.

13. Horwitt M.K., Harvey C.C., Dahm C.H. and Seacy M.T. Relationship between tocopherol and serum lipid levels for determination of nutritional adequacy. Ann. New York Academy of Sciences, 1971; 223-236.

14. Kariuki S.N., Desai M., Muthami N. and Ndombi I.O. Vitamin E levels in sicklers and non-sicklers and the effect of supplementation on the sickling status of African sickle cell anaemia patients in Kenya. In: recent advances in Medical research with a symposium on appropriate technology in disease control. Editors: S.N. Kinoti, P.G. Waiyaki and J.B.O. Were. Proc. 8th Ann. Med. Scient. Conf., Nairobi, Kenya. 1987;168-170.

15. Sauerwein, R.W., Mulder J.A., Mulder L., et al. Inflammatory mediators in children with protein-energy malnutrition. Am. J. Clin. Nutr. 1997; 65:1534-1539.

16. Feillet F., Parra H.J., Kamian K., Bard J.M., Fruchart J.C., Vidailhet M. Lipoprotein metabolism in Marasmic children of Northern Mauritania. Am. J. Clin. Nutr. 1993; 58: 484-488.

17. Davis T.M.E., Binh T.Q., Danh P.T., et al, Serum vitamin $A$ and $E$ concentrations in acute falciparum malaria: modulation or markers of severity? Clin. Sci., 1994; 87: 505-511.

18. Eaton J.W., Eckman J.R., Berger E. and Jacob H.S. Suppression of malaria infection by oxidant-sensitive host erythrocytes. Nature; 1976, 264:758-760. 